\title{
ARTIGOS
}

\section{CULTIVANDO SOCIOLOGIAS PÚBLICAS NOS TERRENOS NACIONAL, REGIONAL E GLOBAL}

\author{
Michael Burawoy
}

\begin{abstract}
RESUMO
Neste artigo o autor discute a posição do sociólogo e dos cientistas sociais como "intelectuais", cuja inserção política e institucional é variada, podendo ser profissional, crítica, pública ou voltada para políticas públicas. Em contraposição a um ideal wallersteiniano - de acordo com o qual o intelectual, por um lado, está mais próximo das camadas populares e mais distante do poder e, por outro lado, tem uma responsabilidade ao mesmo tempo analítica, moral e política -, o autor considera que os cientistas sociais podem adotar apenas uma dessas dimensões de cada vez, mas que as trocas entre os gêneros da prática sociológica integram, de maneira positiva, a sua dinâmica profissional. O artigo tem a seguinte estrutura: 1) situa o sociólogo no contexto da sua prática, dando especial atenção ao caráter disciplinar vigente; 2) o qual é ele próprio conformado por diferentes regimes políticos nacionais; 3) para finalmente tratar do âmbito global. A conclusão geral é que os sociólogos não orbitam em um espaço vazio além da economia, mas cumprem suas missões em terrenos ideológico e político, que são locais e nacionais antes de constituírem-se como globais. Reconhecer esses terrenos é a primeira tarefa para qualquer engajamento crítico ou projeto político, pois eles constituem os tijolos de qualquer Sociologia internacional.
\end{abstract}

PALAVRAS-CHAVE: Sociologia pública; níveis nacional e global; intelectual; Wallerstein; prática profissional.

\section{INTRODUÇ̃̃O}

No artigo titulado "Knowledge, Power and Politics: The Role of the Intellectual in the Age of Transition"2 publicado no boletim eletrônico da Associação Internacional de Sociologia [ISA, na sigla em inglês] no verão de 2005, Immanuel Wallerstein escreve que o papel do intelectual é hoje decisivo. Estamos em um período transitório

\footnotetext{
${ }^{1}$ Este texto foi originalmente proferido como discurso na Conferência do Conselho das Associações Nacionais, ligado à Associação Sociológica Internacional (ISA), realizada em Miami entre 9 e 10 de agosto de 2005. O texto vem sendo desde então revisado com base nos artigos apresentados e nas discussões que se desenrolaram. Gostaria de agradecer a todos os participantes daquele tão estimulante encontro, especialmente a seus organizadores: Sujata Patel e Doug Kincaid. Por fim, voltando a Berkeley, tenho contado com a perspicácia de Peter Evans. Título original: Forging public sociologies on national, regional and global terrains; tradução de Fernando Rogério Jardim e revisão da tradução de Gustavo Biscaia de Lacerda.

2 Em inglês, no original: "Conhecimento, poder e política: o papel do intelectual na era da transição" (nota do tradutor).
}

em que "A clareza da análise é freqüentemente obscurecida pelas realidades caóticas e seus arroubos emocionais imediatos. Mas se os intelectuais não segurarem bem alto a bandeira da análise é pouco provável que outros fá-lo-ão. E se a compreensão analítica das alternativas históricas reais não estiver no primeiro plano do nosso pensamento, nossas escolhas morais poderão ser falhas e sobretudo nossa força política será solapada" (WALLERSTEIN, 2005). As incertezas da transição exigem intelectuais capazes de mapear nossos caminhos rumo ao futuro: eles guiarão nossas visões morais e também a sua realização política.

Wallerstein argumenta que desde 1968 o sistema mundial tem passado por uma profunda crise econômica, portanto viveríamos hoje um período transitório. Assim, há urgência na análise das suas possíveis direções. Além do mais, a crise econômica perturbou os sistemas epistemológicos globais, dissolvendo a antiquada divisão entre as $\mathrm{Hu}$ manidades e as Ciências Naturais, tornando possível a unificação de todo o conhecimento ao redor das Ciências Sociais - as quais têm abandonado elas próprias as suas fronteiras disciplinares 
anacrônicas. Wallerstein apresenta-nos sua agora familiar visão, formulada no relatório da Comissão Gulbenkian - Abrir as Ciências Sociais (WALLERSTEIN, 1996) -: a visão de um conhecimento universal que os intelectuais mobilizarão para o entendimento analítico das alternativas históricas reais, informando nossas escolhas morais, as quais eles tentarão realizar politicamente. Nesse processo, adverte Wallerstein, os intelectuais não serão populares junto "àqueles no poder", junto "àqueles na oposição" e mesmo junto "àquelas numerosas camadas trabalhadoras". Mas eles deverão assumir sua responsabilidade e executar todas as três tarefas - analítica, moral e política definidoras da vocação do intelectual.

Nada errado com isso enquanto ideal - enquanto ideal moral, se se preferir, talvez alcançável em um sistema mundial futuro. O único problema é seu caráter abstrato. Nós pouco sabemos acerca das possibilidades e dos obstáculos para sua realização aqui e agora; por exemplo, os dilemas ao afirmar-se simultaneamente analítico, moral e político! Isso sem falar dos interesses subjacentes aos conhecimentos disciplinares, os quais não vão simplesmente desaparecer só porque para uns e outros eles parecem arbitrários. Wallerstein também omite - o que é paradoxal em se tratando do principal analista dos sistemas mundiais e de alguém que tanto fez pela promoção das sociologias regionais - qualquer consideração sobre o contexto dentro do qual diferentes intelectuais operam em distintas partes do mundo e em distintos períodos da história. Também ausente está toda a compreensão do âmbito político mais amplo dessa "era de transição". E estamos esquecendo-nos precisamente do momento empírico-analítico necessário para transformar a visão moral em luta política - o momento empírico-analítico que Wallerstein defende ser tão central e tão importante.

Deixando para trás questões como se existe algum sistema mundial obedecendo a suas próprias leis; se ele esteve sob prolongada crise econômica durante 40 anos devido aos custos ascendentes da acumulação capitalista; se as crises econômicas dão origem a transformações na sociedade ou constituem os veículos por meio dos quais o capitalismo reestrutura a si mesmo; se as crises econômicas geram automaticamente aberturas políticas ou se a política tem sua autonomia própria; enfim, pondo de lado essas importantes ques- tões, eu desejo no entanto discorrer mais detidamente sobre a micropolítica da produção e da difusão do conhecimento. Focalizarei o sociólogo, não como um "intelectual total" wallersteiniano, mas como um humilde especialista intelectual que não pode perseguir o analítico, o moral e o político ao mesmo tempo.

Minha abordagem avança de baixo para cima em três etapas: 1) situa o sociólogo no contexto da sua prática, dando especial atenção ao caráter disciplinar vigente em seu conhecimento; 2 ) o qual é ele próprio conformado por diferentes regimes políticos nacionais; 3 ) para finalmente me mover para o âmbito global. Em sua composição etnográfica, os sociólogos não orbitam em um espaço vazio além da economia, mas cumprem suas missões em terrenos ideológico e político terrenos que são locais e nacionais antes de constituírem-se como globais. Reconhecer esses terrenos é a primeira tarefa para qualquer engajamento crítico ou projeto político, pois eles constituem os tijolos de qualquer Sociologia internacional.

\section{A DIVISÃO DISCIPLINAR DO TRABALHO}

Ao expressar seu "conhecimento universal" em termos disciplinares, Wallerstein esquece as diferenças genuínas e fundamentais na abordagem intelectual, provenientes das posições amplamente discrepantes a partir das quais os sociólogos (e os intelectuais mais genericamente) empreendem seu trabalho em diferentes contextos sociopolíticos ao redor do globo. Precisamos de um aparato conceitual para dar relevo à existência e à vitalidade dessas práticas divergentes. Proponho fazê-lo levantando duas questões críticas ofuscadas por Wallerstein: conhecimento para quem? Conhecimento para quê? São questões com validade universal, porém com respostas específicas histórica, geográfica e até biograficamente. Tais questões obrigam a Sociologia a confrontar a lógica e o contexto da sua prática.

Primeiramente: Sociologia para quem? Conforme as propostas do presente ensaio, eu faço distinção aqui entre duas grandes audiências: de um lado, produzimos conhecimento uns para os outros, enquanto comunidade de acadêmicos e de cientistas procurando entender melhor o mundo e desenvolver nossas pesquisas; por outro lado, produzimos conhecimento para outras pessoas além da academia, para serem elas mais efetivas no mundo. $\mathrm{O}$ conhecimento sociológico auxilia 
os indivíduos a compreenderem seu lugar no mundo, bem como as estratégias para fazerem o que podem e o que devem a respeito disso. Essa divisão entre as audiências acadêmicas e as audiências extra-acadêmicas implica que a Sociologia não se pode reduzir a seus momentos ativista ou pragmático, mas possui seu indispensável momento acadêmico, requerendo autonomia relativa própria. Igualmente, a necessidade de uma tal autonomia não nos faz denegar a responsabilidade frente a nossa pesquisa e a suas implicações para aqueles grupos fora da academia - os quais poderiam beneficiar-se do conhecimento sociológico. As respostas e as reações deles, por sua vez, constituem o laboratório vivo das nossas pesquisas.

Isso nos leva à segunda questão sobre como diferentes grupos podem beneficiar-se da Sociologia: conhecimento para quê? Aqui eu distingo entre, de um lado, um conhecimento instrumental no qual os fins são tidos como dados e em que a proposta é encontrar os meios que melhor atingirão aqueles fins e, por outro lado, um conhecimento reflexivo interessado precisamente em uma discussão aberta e em um exame coletivo daqueles fins ou daqueles valores. Max Weber denominou isso de "discussão axiológica" e Jürgen Habermas, de "ação comunicativa". Essa distinção entre conhecimento instrumental e conhecimento reflexivo é antiga e possui tradição consagrada na Sociologia, tendo sido mais claramente formulada por Max Weber, cujo esquema conceitual da ação social distinguia a racionalidade técnica da racionalidade axiológica. Isso foi depois desenvolvido pela Escola de Frankfurt em uma veia mais crítica - segundo a qual a sociedade capitalista contemporânea, sendo dirigida por mercados e por lucros, tem certa fixação por questões de eficiência e de meios, conseqüentemente perdendo de vista os objetivos últimos, o que atribuíram à "razão". Independentemente da ameaça de um eclipse da razão, é importante para a Sociologia situar na vanguarda da sua análise não apenas o conhecimento instrumental dos meios, mas também o conhecimento reflexivo dos fins.

Essa distinção entre conhecimento instrumental e conhecimento reflexivo, vale lembrar, aplicase tanto à comunidade acadêmica como às intervenções fora da academia. Sendo assim, distinguimos entre a resolução dos enigmas - dirigidos às anomalias e às contradições de nossos programas de pesquisa - na qual tomamos como dados toda sorte de pressupostos de tipo ontológico (como a natureza e o potencial dos seres humanos) e de tipo epistemológico (como as metodologias por meio das quais podemos apreender o mundo); mas, particularmente, pressupostos normativos que necessariamente subjazem a nossas pesquisas. A pesquisa séria no interior de um paradigma, que denomino Sociologia profissional, ao fazer avançar as fronteiras do conhecimento, não pode ao mesmo tempo questionar os fundamentos sobre os quais ela assenta-se. A resolução dos enigmas é o jogo (no sentido sério do termo dado por Bourdieu) em que o foco na jogada pressupõe a concordância quanto a suas regras e a supressão da crítica. Essa "crítica" requer, portanto, certo conhecimento específico e de um tipo peculiar - o qual denomino Sociologia crítica - para interrogar os fundamentos de nossos programas de pesquisa. Célebres expoentes da Sociologia crítica nos Estados Unidos incluem Robert Lynd, Pitirim Sorokin, Wright Mills, Alvin Gouldner e, mais recentemente, Patricia Hill Collins e Dorothy Smith. Cada país tem sua própria tradição de Sociologia crítica, contrabalançando sua Sociologia profissional.

Nós podemos aplicar a mesma distinção a nossas audiências extra-acadêmicas. Por um lado, temos a Sociologia para politicas públicas [policy Sociology], que procura oferecer soluções para problemas definidos por um cliente, por um patrão. Aqui o sociólogo é o especialista que vende seu conhecimento especializado para certo cliente e para determinada tarefa. Exemplos: descobrir quão popular é dado político; desenvolver estratégias de uma campanha de organização sindical; ser a testemunha especialista em um caso jurídico. Alternativamente, os sociólogos para políticas públicas podem servir a patrões como fundações, as quais fornecem financiamento para pesquisa em uma área particular do seu interesse - seja o vírus da aids, seja a Justiça Penal, sejam os direitos humanos. Por outro lado, a modalidade reflexiva do conhecimento extra-acadêmico é a Sociologia pública, que difere da Sociologia para políticas públicas pelo caráter mútuo da relação dos sociólogos com públicos específicos. A função do sociólogo público é problematizar os objetivos tomados como dados pela ciência para políticas públicas [policy science] e fazer isso pelo fortalecimento da autoconsciência dos públicos, por meio do amplo debate sobre valores. Aqui nós podemos distinguir a Sociologia pública tradicional - 
na qual o sociólogo enquanto escritor de um livro famoso é o catalisador da discussão pública - da Sociologia pública orgânica - na qual o sociólogo entra em relação direta com públicos, tais como movimentos sociais e organizações locais. O sociólogo público tradicional fala a partir de um pedestal e sua relação com os públicos é mediada pela imprensa, pela televisão e pela comunicação virtual; já o sociólogo público orgânico trabalha direta e freqüentemente face-a-face com os públicos nas trincheiras da sociedade civil.

Podemos então distinguir diferentes sociologias públicas pela natureza das audiências com as quais ela engaja-se. Considerados como comunidades discursivas com compromissos comparti- lhados, os públicos variam pela densidade de sua interação interna (dispersos versus concentrados), pelo nível de sua mobilização (ativos versus passivos), por sua extensão geográfica (locais, regionais, nacionais, globais) e por sua política (hegemônicos versus contra-hegemônicos). A Sociologia pública tradicional dirige-se a públicos dispersos, passivos, nacionais e hegemônicos; já a Sociologia pública orgânica foca-se nos públicos concentrados, ativos, locais e freqüentemente contra-hegemônicos. Nessa nossa formulação idealtípica, o mais importante é que a Sociologia pública seja o diálogo entre sociólogos e leigos acerca dos valores e objetivos das comunidades às quais pertencem.

TABELA 1 -ADIVISÃO DO TRABALHO SOCIOLÓGICO

\begin{tabular}{|l|c|c|}
\hline & AUDIÊNCIA ACADÊMICA & $\begin{array}{c}\text { AUDIÊNCIA } \\
\text { EXTRA-ACADÊMICA }\end{array}$ \\
\hline $\begin{array}{l}\text { CONHECIMENTO } \\
\text { INSTRUMENTAL }\end{array}$ & Sociologia profissional & $\begin{array}{c}\text { Sociologia para } \\
\text { políticas públicas }\end{array}$ \\
\hline Conhecimento & Teórico / Empírico & Concreto \\
Verificação & Correspondência & Pragmático \\
Legitimidade & Normas científicas & Eficácia \\
Prestação de contas & Pares & Clientes / Patrões \\
Patologia & Auto-referência & Servilismo \\
Política & Auto-interesse profissional & Intervenção prática \\
& & Sociologia pública \\
\hline CONHECIMENTO & Sociologia crítica & Comunicativo \\
REFLEXIVO & & Consenso \\
\hline Conhecimento & Fundacional & Relevância \\
Verificação & Normativa & Públicos designados \\
Legitimidade & Visão moral & Modismo \\
Prestação de contas & Intelectuais críticos & Diálogo público \\
Patologia & Dogmatismo & \\
Política & Debate interno & \\
& & \\
\hline
\end{tabular}

FONTE: 0 autor.

O resultado é a Tabela 1 acima, classificando a Sociologia pelo cruzamento do conhecimentopara-quem com o conhecimento-para-quê, tendo por finalidade gerar quatro sociologias discrepantes, divergindo em sua forma de produção, em seu critério de verificação, em seu modo de legitimação, em sua prestação de contas, em suas patologias e políticas. Embora sem espaço para desenvolver aqui cada tipo de conhecimento, ao longo das seis dimensões apresentadas, a tabela resume as diferenças que definem as quatro subculturas da nossa disciplina, expressas por diferentes valores, modos de avaliação, formas de comunicação etc.

Esses não são simplesmente quatro tipos desconexos do conhecimento; eles dependem reciprocamente uns dos outros, mesmo quando estão em contradição. Assim, por exemplo, o conhecimento profissional envolve o intercâmbio da teoria com o dado empírico; seu critério de verificação é a correspondência com a realidade; sua legitimação é baseada em normas científicas; sua 
prestação de contas é com os pares e sua política é o auto-interesse profissional. Sua patologia é a auto-referência. Já a Sociologia pública, por sua vez, é desenvolvida pela comunicação dos sociólogos (levando conhecimento analítico) com os públicos (levando conhecimento tradicional e senso comum). Aqui a verdade é mensurada pelo consenso atingido pelos dois parceiros no diálogo. Sua legitimação é baseada em sua relevância para esses públicos, o que facilmente leva vantagem sobre o conhecimento profissional, freqüentemente incompreensível para certas audiências. A Sociologia pública presta contas a públicos designados, os quais a põem em uma tensão com a Sociologia profissional e com a responsabilidade desta perante os pares. Sua política envolve o diálogo público, o qual pode mesmo ser ameaçado pela autodefesa profissional. Aqui a patologia não é a auto-referência, o ensimesmamento, mas é a demagogia [pandering to publics], o modismo [faddishness]. Ao mesmo tempo que são antagônicos, os dois conhecimentos também são interdependentes: o conhecimento profissional é inspirado pelos impulsos vindos da Sociologia pública, assim como o conhecimento público mal pode subsistir sem a contribuição da Sociologia profissional. Eu poderia desenvolver argumentos paralelos acerca das interdependências antagônicas entre os outros dois tipos do conhecimento sociológico.

Esses quatro conhecimentos formam, portanto, subculturas distintas, conectadas reciprocamente por meio de uma divisão do trabalho sociológico. Quando tais subculturas perdem seu vigoroso intercâmbio recíproco - seja porque convirjam, seja porque divirjam - elas assumem formas patológicas que ameaçam a disciplina no seu todo. Wallerstein está certo ao enfatizar as funções da análise (Sociologia profissional), da visão moral (Sociologia crítica) e da ação política (Sociologia para políticas públicas e Sociologia pública); entretanto, ele não analisa como seus projetos distintos formam interdependências antagônicas; como cada qual requer suas próprias especialização e autonomia relativa - o que não impossibilita, antes medeia, as influências externas. Wallerstein nem sequer admite as armadilhas e os perigos intrínsecos a cada conhecimento quando ele só persegue suas práticas distintivas.

É claro, tudo isso é mais complicado do que tenho enunciado até aqui. Cada conhecimento especializado é ele próprio compartimentado internamente ao longo das mesmas divisões (conheci- mento-para-quem e conhecimento-para-quê). Existem, por exemplo, momentos crítico, público e para políticas públicas no interior da Sociologia profissional. Em adição a essa complexidade intrínseca a cada quadrante, nós também devemos reconhecer uma distinção entre o tipo de conhecimento e os indivíduos que o produzem. A especialização pode ser necessária, mas isso não significa que dado sociólogo terá seu pé sempre fincado em um só tipo. Longe disso! Muitos sociólogos transpõem os diferentes tipos do conhecimento e sobretudo suas carreiras seguem diferentes rotas por meio dos quatro quadrantes. Nessa (di)visão do trabalho sociológico, a interdependência não significa, por exemplo, que alguém precise ser sociólogo público para contribuir para a Sociologia pública; alguém pode fazer isso indiretamente, através da sua Sociologia profissional, crítica ou para políticas públicas. Não há espaço para desenvolver aqui esses aspectos da divisão do trabalho sociológico, pois estou interessado apenas nas variações nacionais e históricas da divisão desse trabalho.

\section{DOS REGIMES NACIONAIS AOS REGI- MES REGIONAIS}

Por detrás da divisão do trabalho sociológico, jaz a idéia de uma solidariedade orgânica na qual o florescimento de cada tipo de Sociologia é a condição para o florescimento do todo. Na medida em que cada tipo mantiver intercâmbios contínuos com os outros e evitar fechar-se em si mesmo ou tornar-se presa das forças externas, a Sociologia prosperará. Na realidade, a interdependência recíproca entre as quatro sociologias raramente é atingida sem alguma hierarquia entre elas - chame-se isso de campo de poder, se se preferir - a qual varia conforme o tempo e o lugar.

Assim, se alguém analisar historicamente o desenvolvimento do campo sociológico nos Estados Unidos, verá certa Sociologia pública surgir das associações religiosas e reformistas nos períodos anterior e imediatamente posterior à Guerra Civil ${ }^{3}$. É interessante notar como a primeira Sociologia surgida nos Estados Unidos foi a apropriação por parte dos estados do Sul das idéias de Comte de

\footnotetext{
3 A Guerra Civil norte-americana, ou Guerra da Secessão, ocorreu entre 1861 e 1865 entre os estados escravocratas do Sul, contrários à abolição da escravatura, e os estados industrializados do Norte, favoráveis à abolição (nota do revisor da tradução).
} 
"ordem e progresso", para desenvolver uma ideologia justificadora da escravidão ${ }^{4}$ - uma ideologia denunciadora da degeneração social dos estados do Norte industrializado. A entrada da Sociologia nas universidades, no período posterior à Guerra Civil e especialmente na Era Dourada ${ }^{5}$, foi mesclada com a prédica da reforma social e inspirada por idéias utópicas, tendo encabeçado lutas para além dos limites da liberdade acadêmica. Uma vez reunidos no interior de uma única Ciência Social, durante as crescentes lutas de classes nos anos 1890, os economistas profissionaliza-ram-se, deixando para trás os sociólogos a perseguirem suas visões mais radicais. Por volta da virada do século [XIX para o $\mathrm{XX}$ ] e durante a Era Progressista ${ }^{6}$, porém os patrocinadores privados das universidades e seus administradores conseguiram com sucesso conter o comprometimento público da Sociologia. Daí então a Sociologia seguiu o caminho da Economia para dentro do mundo da profissionalização, com revistas acadêmicas, livros especializados, programas de pós-graduação, carreiras planejadas, linguagem esotérica, hierarquias etc.

Se o primeiro período foi marcado pelo diálogo entre a Sociologia profissional e a Sociologia pública, o segundo período - começando com a formação da Associoação Sociológica Estadunidense em 1905 e estendendo-se ao longo do período entre-guerras até os anos 1960 - envolve o diálogo entre as sociologias profissional e para políticas públicas. Sob a supervisão dos ca-

\footnotetext{
4 Na verdade, trata-se de uma observação teórica incorreta, a partir de uma apropriação política indevida: Augusto Comte repudiava a escravidão moderna, tendo sido por exemplo uma referência teórica para o abolicionismo do Brasil (N. R. T.)

5 No original, em inglês: "Gilded Age", período da história estadunidense por volta dos anos 1870, marcado por materialismo crasso e corrupção política explícita. Inspirou importantes romances de crítica política e de denúncia social, inclusive o livro escrito por Mark Twain e Charles Warner, donde foi tirada a expressão: "The Gilded Age" (1873) (N. T.).

6 No original em inglês: "Progressive Period", também conhecido como "Progressive Movement". Ele foi o período da história estadunidense entre 1890 e 1924, marcado por ampla reforma social e programas econômicos, incluindo voto feminino, lei seca, diminuição da jornada de trabalho, eliminação do trabalho infantil, adoção de programas assistenciais e de tributação sobre a renda, conservação dos recursos naturais e uso do referendo popular. Figuras importantes dessa época foram Theodore Roosevelt e Woodrow Wilson (N. T.)
}

pitães da indústria e de suas fundações, a Sociologia enquadrou sua pesquisa nos termos do controle social - o tema dominante após a I Guerra Mundial no então crescentemente hegemônico departamento no campo [sociológico], o Departamento de Sociologia da Universidade de Chicago, como também em outro departamento-líder, o da Universidade de Colúmbia. A Sociologia desenvolveria e mobilizaria sua ciência na busca da regulação das populações subalternas - fossem os imigrantes vindos da Europa, fossem os migrantes negros vindos dos estados do Sul rumo às cidades do Norte, fossem os militantes das classes trabalhadoras dos anos 1930. Se inicialmente as fundações privadas foram as principais financiadoras da pesquisa sociológica, nesse novo período o governo federal também se tornou mais diretamente envolvido, especialmente durante a II Guerra Mundial, após a qual o financiamento federal jorrou aos borbotões. Feito isso, a sintonia fina da Sociologia passou do controle social para o consenso axiológico - a base da teoria da modernização, louvando a América como a terra prometida.

A celebração messiânica dos Estados Unidos e a intensificação da aplicação da Sociologia a questões relacionadas às políticas públicas levaram à reação dos anos 1960, receptiva aos movimentos sociais e aos clamores das ruas - direitos civis, protestos contra a guerra, feminismo e assim por diante. Nesse terceiro período, desenvolveu-se a Sociologia crítica da Sociologia profissional, bem como o entrincheiramento desta última no mundo das políticas públicas. Tanto a grande teoria que forneceu o fundamento científico do consenso axiológico como o empirismo abstrato ligado à pesquisa de mercado estiveram sob ataque. Figuras notáveis como C. Wright Mills e Alvin Gouldner captaram a crescente sensação da nova geração, segundo a qual a Sociologia vendera sua alma ao demônio do establishment. Durante os anos 1970, a Sociologia respondeu aos múltiplos desafios do marxismo, do feminismo e da teoria racial crítica por meio ao absorver as críticas e, de fato, mover toda a disciplina para a esquerda do espectro político. Mas assim que o clima político moveu-se para a direita, nas eras Reagan e Bush ${ }^{7}$, a Sociologia perdeu suas garras radicais, embora ela ainda continue à esquerda do público norte-americano. As questões agora são: 1) se a Sociologia

\footnotetext{
7 Anos 1981-1989 (governo Reagan) e 1989-1993 (gover-
} no George Bush, pai) (N. R. T.). 
estadunidense está prestes a lançar-se no quarto período de um renovado diálogo entre a Sociologia profissional e a Sociologia pública e 2) qual papel ela desempenhará na arena internacional.

A história da Sociologia estadunidense que apenas esbocei é marcada pelo amplo predomínio de uma poderosa Sociologia profissional, que, em aliança com a Sociologia para políticas públicas, domina e às vezes até suprime as sociologias crítica e pública. Em outras palavras, trata-se da história de um ascendente - contestado e sempre incompleto - do conhecimento instrumental sobre o conhecimento reflexivo. Tracei essa história não apenas para mostrar a utilidade das minhas categorias, mas também para opor-me à tentação de recalcar o passado e de eternizar o presente; além disso, para sugerir que assim como o presente é diferente do passado, o futuro também será diferente do presente. Eu desejo ademais me opor à noção da Sociologia norte-americana como algo estático e invariável - modelo homogêneo a ser copiado ou rejeitado por outras sociologias, uma norma diante da qual elas são avaliadas ou avaliam a si mesmas como mais ou menos desviantes.

Fazemos nossa própria Sociologia, mas não sob as condições de nossa própria escolha. Isso se aplica a outras nações, bem como aos Estados Unidos. Assim, enquanto muitos países do hemisfério Sul mal podem ter uma Sociologia profissional independente, aqueles que a têm, tais como o Brasil, a África do Sul, o México e as Filipinas, freqüentemente exibem uma Sociologia pública igualmente forte. Os estados nórdicos, com seus estados de bem-estar social, têm tradicionalmente possuído uma forte Sociologia para políticas públicas e o perfil público da sua Sociologia pode ser tão forte quanto o da Economia. É mais difícil encontrar países em que a Sociologia seja dominada por seu momento crítico, embora ela tenha sido forte na França e, sobretudo, na Alemanha a pátria da teoria crítica. Pode-se argumentar que os movimentos dissidentes das sociedades soviéticas, sendo com freqüência potencialmente sociológicos em sua disposição, mostrou inclinação similar para a crítica ${ }^{8}$.

8 Meus dados são limitados. Portanto, o mapeamento a seguir é apenas preliminar e esquemático. Baseei-me e contei com a minha experiência de pesquisa sobre a antiga União Soviética e a Europa Central, minha longa e duradoura ligação com o Sul da África, minhas leituras sobre a Índia, minha constante familiaridade com a Europa ocidental enquanto
O dinamismo das divisões nacionais do trabalho sociológico pode ser melhor analisado por meio da lente das transições políticas. Assim, podemos falar em regimes pós-coloniais como aqueles tentando lidar com as heranças do colonialismo. Isso é bastante evidente na Índia, por exemplo, onde a Sociologia tem estado indissociavelmente ligada à Antropologia e especialmente à Antropologia Social britânica, malgrado a importação da Sociologia do desenvolvimento norte-americana. Reflexiva das heranças coloniais, a Sociologia indiana exibe certa relação ambivalente com a Ciência Social ocidental. A Índia, sobretudo, não tem sido a morada só da Antropologia Social, mas também dos estudos subsidiários que combatem a profunda influência dos discursos ocidentais da modernidade, ao procurar alternativas fomentadas pelas classes mais baixas. Mesmo assim, com sua vasta rede de universidades e de faculdades e alguns proeminentes institutos para pesquisa social, a Sociologia indiana é fortemente enraizada na academia: sua presença pública e política ainda é relativamente muda.

Bem diferente é a herança do comunismo soviético, que, por sua vez, matou e ressuscitou a Sociologia como instrumento ideológico. Assim, não é surpreendente que a Sociologia nos regimes pós-comunistas tenha sido geralmente hostil ao marxismo e freqüentemente combinada com certa receptividade acrítica do pensamento ocidental, particularmente da Sociologia norte-americana. Enquanto alguma Sociologia pública brevemente floresceu na União Soviética sob a perestroika e durante o crepúsculo do comunismo, sem ter o histórico de uma autonomia profissional, a Sociologia pós-comunista rapidamente caiu presa da pesquisa para políticas públicas - enquete de opinião para políticos e pesquisa de mercado para corporações ocidentais. Embora pesquisas usando métodos quantitativos pudessem desempenhar algum papel crítico sob o comunismo, em que a divulgação da opinião pública efetivamente desafiava as alegações da ideologia do partido, elas certamente não têm feito o mesmo agora. A verdadeira Sociologia crítica - reflexiva e normativa - do samizdat ${ }^{9}$ aguarda a nova geração de intelec-

vivo nos Estados Unidos e meu namoro com a Sociologia latino-americana, bem como longos anos trabalhando com pós-graduandos que estudam diferentes regiões do mundo.

9 Palavra russa cujo significado aproximado é "edição independente". Refere-se à literatura marginal escrita, publicada e distribuída secretamente por dissidentes soviéticos a partir do fim do stalinismo (N. T.). 
tuais com inclinação sociológica, que deverão seguir os passos de um Havel na Checoslováquia, de um Kolakowski na Polônia ou de um Konrad e de um Szelenyi na Hungria.

Embora a tendência dominante hoje seja rumo à crua ciência para políticas públicas, há também divergências entre os regimes pós-comunistas, que refletem os variados estatutos da Sociologia sob o comunismo. Assim, a Sociologia esteve livre para desenvolver-se na Polônia e na Hungria; foi suprimida na Romênia e na Checoslováquia, enquanto na Bulgária ela desenvolveu-se expressivamente sob a cuidadosa tutela do Estado. Refletindo as variações na medida da liberdade política permitida sob o socialismo estatal, tais divergências têm desde então produzido ênfases algo diferentes no tocante à centralidade da Sociologia para políticas públicas.

O diálogo entre as sociologias profissional e crítica - nos regimes pós-coloniais - e o diálogo entre as sociologias profissional e para políticas públicas - nos regimes pós-comunistas - igualmente contrastam com o diálogo entre as sociologias profissional e pública - nos regimes pósautoritários. Em diversos países da América Latina, a revogação da ordem ditatorial conduziu ao surgimento de uma Sociologia pública eficaz e libertária, que tem sido promovida por bolsões de liberdade, com freqüência sustentados por redes continentais de apoio. Os regimes autoritários nem controlaram a Sociologia na mesma medida dos regimes comunistas, nem forjaram estreitas conexões com os países metropolitanos, como os regimes coloniais. Os sociólogos latino-americanos estavam aptos então a construir alianças e a valerem-se do pensamento crítico europeu, tendo por finalidade desenvolver essa Sociologia nacional e engajada que floresceu após as ditaduras militares. Espalhando-se para dentro da sociedade civil, ela tornou-se o protótipo da Sociologia pública. Aqui talvez possamos incluir os dois países da Europa meridional que também viveram sob regimes autoritários por longo tempo Espanha e Portugal.

Assim como com o pós-colonialismo e com o pós-comunismo, há grande variação ao redor da tendência central, dependendo da especificidade do legado autoritário. Por exemplo: foi no exílio no Chile e durante o governo de Salvador Allende que Cardoso uniu-se a Falleto para escrever seu Dependência e desenvolvimento na América La- tina (CARDOSO \& FALETTO, 1970) - esse clássico das sociologias crítica e pública, que também deu início à Sociologia profissional do desenvolvimento. Hoje a Sociologia brasileira tem forte presença pública - o que é inimaginável dizer da perspectiva dos Estados Unidos. As variações na configuração da divisão do trabalho sociológico dentro da América Latina devem ser analisadas em relação tanto ao passado como quanto aos regimes políticos presentes. Muito freqüentemente, a efervescência das sociologias públicas requer o amparo de uma Sociologia profissional - situação exatamente oposta à dos Estados Unidos. Indo para outro continente, o caso da África do Sul é interessante, pois, embora carregue as marcas da Sociologia pós-colonial, em diversos aspectos ela é mais parecida com o modelo pós-autoritário da América Latina. A Sociologia prosperou na oposição ao apartheid e continua aquele mesmo engajamento cívico no período pós-apartheid, embora ela esteja hoje muito mais ameaçada pela cooptação do Estado e pela desmobilização da sociedade civil.

$\mathrm{Na}$ falta de um termo melhor, denomino de sociedades pós-industriais o quarto complexo das configurações disciplinares das Europas Ocidental e Setentrional. A economia desses países tem crescentemente abandonado a indústria pesada $\mathrm{e}$ mudado rumo ao setor de serviços - mudança que é refletida igualmente na estrutura da disciplina sociológica e em seus interesses mais prioritários. Há certo desvio das questões tradicionais como Sociologia Industrial e movimentos operários em direção a temas como novos movimentos sociais, tempo livre, questões de gênero, comunicações de massa etc. Aqui a Sociologia nem foi tão desenvolvida profissionalmente, nem é tão delineada frente às outras disciplinas, como acontece nos Estados Unidos. Em conformidade com isso, as sociologias pública e para políticas públicas são bem desenvolvidas. Podemos dividir essa região em duas sub-regiões: a Europa Setentrional, com seus estados de bem-estar social mais desenvolvidos, têm uma Sociologia para políticas públicas mais forte; já a Europa Meridional, com suas políticas e sociedades civis mais vibrantes, têm uma Sociologia pública mais forte. Em ambas as sub-regiões, entretanto, as sociologias pública e para políticas públicas tendem a reforçar-se mutuamente.

O caso da Inglaterra é interessante, estando ela no meio-termo das duas sub-regiões. Com longa tradição de administração social, intimamente 
conectada primeiro com o socialismo evolucionista fabiano e depois com o nascimento do Estado assistencial, a Sociologia teve desenvolvimento tardio nos anos 1960, surgindo como tal só com a expansão do sistema universitário. Dado seu desenvolvimento tardio, suas fronteiras eram porosas, obtendo fomento das disciplinas vizinhas: Economia, Antropologia, Geografia e História, bem como da teoria social européia. Ela foi muito mais desconfiada (senão abertamente hostil) à Sociologia norte-americana. Sendo ministrada no Ensino Médio, a Sociologia fincou raízes profundas na sociedade, que nem as políticas antissociais do governo Thatcher puderam destruir. Hoje a Sociologia não apenas existe como força no debate público, mas também nas crescentes consultorias junto às agências estatais, especialmente para avaliação das políticas públicas.

Max Weber foi o primeiro a analisar sistematicamente o contexto político da Ciência Social acadêmica, cunhando o conceito de uma ciência axiologicamente neutra. Sua análise das universidades alemãs mostrou que os sociólogos não operam em um vácuo ideológico e político. Ele opôsse à interferência política - fosse na negação de posições universitárias a talentosos acadêmicos por serem eles social-democratas, fosse a nomeação de porta-vozes do governo como professores. Nessas circunstâncias, era importante afirmar a autonomia profissional. Tentei desenvolver seus argumentos em um contexto histórico bastante diferente, ao esboçar os parâmetros da divisão disciplinar do trabalho (o terreno ideológico) e a forma pela qual, por sua vez, ela é enquadrada pelos regimes políticos e por suas transformações.

Embora o prefixo "pós" seja conceitualmente frouxo, ele é útil para destacar as heranças que constrangem (embora nunca determinem) as trajetórias nacionais. $\mathrm{O}$ "pós" permite-nos identificar constelações de sociologias nacionais que compartilham uma história comum - uma base para diálogos regionais acerca das diferenças e das semelhanças [commonalities] e um lócus para desenvolver a compreensão das peculiaridades nacionais. Tais associações regionais podem fortificar a coluna vertebral crítica e pública das sociologias nacionais, especialmente quando elas estão sob a pressão estatal para instrumentalizá-las; justamente porque tais associações podem mesmo fortalecer a contestação às hegemonias globais, contribuindo assim para a emergente Sociologia internacional.

\section{RECOMPONDO O TERRENO DA SOCIO- LOGIA INTERNACIONAL}

As divisões nacionais do trabalho sociológico não são autônomas; elas são afetadas por uma divisão global mais ampla do trabalho sociológico - uma divisão global emergente das sociologias profissional, crítica, pública e para políticas públicas. Assim, não é surpreendente que a Sociologia profissional global seja dominada pelos Estados Unidos - que se ergue tal como um leviatã, com sua concentração de recursos, ostentando mais de 200 revistas científica, cerca de 14000 membros da Associação Sociológica Americana, mais que o dobro disso em doutores ativos e seus generosos recursos para pesquisa vindos de fontes privadas e públicas (generosos pelo menos quando comparados com quaisquer outros países, quanto não com outras disciplinas). Todos os anos, as universidades bombeiam mais de 600 doutores e 25000 bacharéis em Sociologia. O sistema educacional norte-americano tem sua própria hierarquia interna, é claro, com seu sistema de prestígio cuidadosamente calibrado, de modo que a divisão do trabalho sociológico parece bem diferente em uma faculdade estatal quando comparada com alguma universidade privada ligada à pesquisa ${ }^{10}$. Mesmo assim, o rótulo de um doutor norte-americano - seja lá de onde tenha vindo possui alto valor na maior parte do mundo, nas universidades e nas agências governamentais. E seja qual for a hostilidade aos Estados Unidos, ela pouco limita a oportunidade de uma graduação ou pós-graduação ou de uma bolsa de pesquisa nos Estados Unidos. O tempo gasto nos Estados Unidos traz bom retorno à carreira no país de origem. Dessa forma, a Sociologia profissional norte-americana imprime sua marca sobre as sociologias profissionais nacionais, como ponto de referência hegemônico.

Essa influência é especialmente grande nos protetorados [clientalist states], como Israel e Taiwan, em que a maioria dos sociólogos-líderes é treinada nos Estados Unidos e em que uma publicação em uma grande revista científica norte-

10 Diferentemente do sistema universitário brasileiro, no caso norte-americano as universidades privadas, especialmente aquelas ligadas à pesquisa, têm prestígio superior ao das faculdades estatais (N. T.). 
americana conduz a postos no topo da hierarquia do prestígio. Mas mesmo aqui a situação não é tão simples quanto parece. Em Taiwan há uma apropriação seletiva da Sociologia norte-americana, manifesta em um conflito entre gerações, com uma Sociologia mais reflexiva reivindicada por aqueles influenciados pelos movimentos estudantis do final dos anos 1980 e início dos anos 1990 , opondo-se à Sociologia instrumental do establishment ${ }^{11}$. Em Israel, enquanto as principais universidades estão com efeito orientadas para os Estados Unidos, os sociólogos com estatuto inferior e as faculdades recentemente criadas estão orientados para as questões das comunidades locais - sendo expoentes das sociologias crítica e pública. A Sociologia palestina, sitiada pela ocupação e lutando pela sobrevivência, é quase inevitavelmente crítica e pública.

Malgrado as tendências contrárias, a indicação de desempenho [benchmarking] da pesquisa científica (incluindo a sociológica) para publicações em revistas "internacionais" vem-se tornando mais e mais comum ao redor do globo - e não apenas naqueles países atados aos Estados Unidos por motivos geopolíticos. A Fundação Nacional para Pesquisa da África do Sul, por exemplo, classifica os pesquisadores com base no seu perfil internacional e conseqüentemente afastando dos assuntos locais e nacionais o melhor da pesquisa, aproximando-a dos temas que interessam aos "porteiros" das revistas norte-americanas ${ }^{12}$. Mesmo em um país rico como a Noruega, a tendência vai na mesma direção, arrastando a ciência para dentro das redes competitivas internacionais. A superfície da Sociologia na China - esse intrigante e complexo caso de desenvolvimento tardio - também tem-se aproximado dos padrões mais conservadores da Sociologia norte-americana, com espaço limitado (senão ausente) para as sociologias crítica e pública. Tais modelos de referência internacional podem funcionar bem para as Ciências Naturais, mas são um verdadeiro desastre para as Ciências Sociais, cujo florescimento depende da sua conexão com as questões locais. Essas adoções estrangeiras geralmente não são o resultado de um projeto imperialista dos Estados Uni-

11 Meus agradecimentos a Hwa-Jen Liu pela ajuda em desembaraçar as diferentes linhas da Sociologia de Taiwan.

12 A situação brasiliera, com o sistema Qualis, é semelhante a essa descrita (N. R. T.) dos para controlar as sociologias nacionais, mas são, mais usualmente, impulsionadas pelos interesses internos dos Estados nacionais e suas elites acadêmicas.

A hegemonia da Sociologia profissional estadunidense não se faz sem contestação. Da Europa, especialmente da França e da Alemanha, pátrias tradicionais da Sociologia, têm surgido poderosas sociologias críticas. Alain Touraine e mais diretamente Pierre Bourdieu têm atacado a Sociologia estadunidense por seu pretenso universalismo, pelo seu obscurecimento das classes e mais genericamente por sua pouca reflexividade. De maneira semelhante, Jürgen Habermas, continuando a tradição da Escola de Frankfurt, tem desafiado as limitações do "positivismo", ou mais genericamente o que eu chamei de conhecimento instrumental, a partir da perspectiva da teoria crítica e da ação comunicativa, que eu chamei de conhecimento reflexivo. Da perspectiva do hemisfério Sul, porém, a Sociologia européia pode representar o capital simbólico que apóia - tudo isso mais insidiosamente, devido à sua proclamada veia crítica - à dominação mais silenciosa dos capitais acadêmico e institucional estadunidense ${ }^{13}$. Afinal de contas, tem havido um ativo intercâmbio entre esses dois pólos de dominação, com o fluxo de metodologias de pesquisa para lá e de teoria social para cá. Outra dimensão da teoria crítica, freqüentemente sob o rótulo de estudos pós-coloniais oriundos de países asiáticos, africanos e latino-americanos, têm adotado postura hostil frente a toda ciência social dita "ocidental".

Se a Sociologia profissional estadunidense secretamente conspira em simbiose com a Sociologia crítica européia, o que dizer então da Sociologia para políticas públicas em nível global? Aqui se pode perguntar acerca do lugar da Sociologia em várias agências multilaterais - a Organização das Nações Unidas (ONU), o Banco Mundial, o

13 Dentre os presidentes dos 53 comitês de pesquisa da ISA, são da Europa Ocidental 26 (49\%); vêm dos Estados Unidos 11 (21\%); representam Israel, Canadá, Japão e Austrália oito (17\%), enquanto apenas sete (13\%) são do resto do mundo: Ásia, América Latina e África! A participação de membros individuais da ISA (dados de 2003) é, não surpreendentemente, algo menos enviesada: Europa Ocidental: 32\%; América do Norte [Estados Unidos e Canadá]: 23\%; antiga União Soviética, Europas Oriental e Central: 12\%; Ásia, Oriente Médio e América Latina: 33\%. 
Fundo Monetário Internacional (FMI) e a ampla gama das organizações não-governamentais (ONGs) transnacionais - que empregam cientistas sociais para lidar com suas agendas políticas específicas. Isso resulta, é claro, em que os sociólogos raramente são encontrados em tais corredores do poder, embora as feministas tenham feito incursões na ONU e nas ONGs. Esse geralmente é o território dos economistas, dos contadores e dos advogados, cujos conhecimentos estão melhor sintonizados com as políticas das organizações mundiais. Será muito mais provável encontrarmos sociólogos entre aqueles que criticam o funcionamento dessas agências, questionando a adoção generalizada do modelo único do FMI, aquilo que Peter Evans denominou de "ceifa única" [mono-cropping], ou atacando o Banco Mundial - seja em seu velho épico capa-e-espada da devastação ambiental, seja, como Michael Goldman mostrou, em sua disseminação de novos e mais sutis conhecimentos disciplinares e tecnologias de poder.

Tais críticas às dúbias organizações mundiais surgem de e retroalimentam a sociedade civil transnacional - o solo das sociologias públicas em escala global. O cadinho dessas sociologias públicas pode ser encontrado no Fórum Social Mundial e nos fóruns regionais replicados por ele, vivendo de redes que unem todo tipo de reformistas, anarquistas e lutas radicais contra a globalização. Aqui nós podemos encontrar movimentos operários renovados que se estendem para além das fronteiras nacionais, movimentos ambientalistas, organizações dos direitos humanos, protestos contra a guerra e redes feministas - todos promovendo o engajamento da Sociologia pública no interior de uma esfera pública global e emergente. Inspiradas pelas sociologias críticas, freqüentemente nascidas em âmbitos nacionais, opondo-se às estruturas globais do poder e almejando tornar locais ${ }^{14}$ as sociologias profissionais, especialmente a Sociologia profissional nor-

14 "Provincializing", no original em inglês. Optou-se pela mudança de termo - "tornar local" ao invés de "provincializar" - para evitar a conotação negativa da palavra, o contrário do proposto pelo autor (N. T.). te-americana, as sociologias públicas globais buscam efetivar aqueles valores que têm impulsionado a Sociologia desde o seu início.

Por fim, para retornar a Wallerstein: as sociologias públicas globais são a antítese do projeto dele para a unificação das Ciências Sociais. Qualquer unidade das Ciências Sociais significaria a unidade do mais forte: em termos disciplinares, isso significa uma unidade em torno da economia e seu projeto neoliberal; já em termos geopolíticos, isso representaria uma unidade ao redor dos interesses das bem-providas Ciências Sociais ocidentais. Eu venho, porém, esquematizando o projeto alternativo, cuja energia provém de baixo e procura proteger a integridade das divisões nacionais do trabalho sociológico, por meio da amarração das sociologias pública, crítica, profissional e para políticas públicas. Isso envolve costurar alianças com as sociologias nacionais em associações regionais, desafiando a hegemonia das sociologias estadunidense e européia, enquanto mantêm conexões com as sociedades civis - nacional e transnacional. Tal projeto não perpassará as sociologias acadêmicas dos Estados Unidos e da Europa, mas forçará a européia em direção ao reconhecimento do seu próprio poder, compelindo ao ajuste delas às necessidades, às relações e ao diálogo com as poderosas sociologias públicas, emanando do hemisfério Sul, mas não confinado somente a ele.

Em flagrante contraste com a teoria dos sistemas mundiais que desce do céu para a terra, aqui nós subimos da terra para o céu. Quer dizer: não partimos de uma unidade imaginária do conhecimento nem de um sistema econômico abstrato com leis naturais para daí chegar à Sociologia em carne e osso. Pelo contrário: nós partimos das sociologias realmente existentes, lutando para sobreviver em contextos hostis, e com base em suas divisões do trabalho e em suas vivas conexões com a sociedade civil, cultivamos o jardim da Sociologia internacional ${ }^{15}$.

15 O autor usa "weave the tapestry" ("tecer a tapeçaria") no original. Preferimos deslocar a metáfora para fazê-la combinar com o título do artigo, o qual também foi alterado para evitar a dubiedade da palavra "forjar" em português (N. T.). 
Michael Burawoy (burawoy@berkeley.edu) é Doutor em Sociologia pela Universidade de Chicago e Professor do Departamento de Sociologia da Universidade da Califórnia (campus de Berkeley), ambas nos Estados Unidos.

\section{REFERÊNCIAS BIBLIOGRÁFICAS}

CARDOSO, F. H. \& FALleTO, E. 1970. Dependência e desenvolvimento na América Latina. Rio de Janeiro : J. Zahar.

WALLERSTEIN, I. (ed.). 1996. Opening the Social Sciences : Report from the Gulbenkian
Comission on Reestructuring the Social Sciences. Stanford : Stanford University.

2005. Knowledge, Power and Politics :

The Role of the Intellectual in the Age of Transition. ISA E-Bulletin, Madrid, n. 1, p. 916, Summer. 


\section{CULTIVATING PUBLIC SOCIOLOGIES AT THE NATIONAL, REGIONAL AND GLOBAL} LEVELS

Michael Burawoy

In this article the author discusses the position of sociologists and social scientists as "intellectuals" with varied forms of political and institutional participation - whether professional, critical, public or public policy oriented. In contrast to Wallerstein's ideal, in which an intellectual is closer to the popular classes and at a greater distance from power while maintaining a responsibility that is simultaneously analytical, moral and political, the author believes that social scientists can adopt only one of these dimensions at a time, although the interchange between these types of sociological practice also make up a positive part of its professional dynamic. The article is structured as follows: 1) it situates the sociologist within the context of his/her practice, placing special attention on the current character of the discipline; 2) looks at how the latter is constituted by different national political regimes; 3 ) and finally moves on to the global level. Its most general conclusion is that sociologists do not exist in an empty space removed from the economy, but fulfill their missions in terrains that are ideological and political and local and national before becoming global. To recognize these terrains is the first step to any critical engagement or political project, constituting the building material for any notion of an international sociology.

Keywords: public Sociology; national and global levels; intellectuals; Immanuel Wallerstein; professional practice. 
CULTIVER LES SOCIOLOGIES PUBLIQUES AUX NIVEAUX NATIONAL, RÉGIONAL ET GLOBAL

Michael Burawoy

Dans cet article l'auteur discute de la position du sociologue et des scientifiques sociaux comme « intellectuels », dont l'insertion politique et institutionnelle est multiple : professionnelle, critique, publique ou tournée vers les politiques publiques. Contrairement à un idéal wallesteinien - selon lequel l'intellectuel, d'une part, est plus proche des classes populaires et plus éloigné du pouvoir et, d'autre part, a une responsabilité à la fois analytique, morale et politique -, l'auteur estime que les scientifiques sociaux ne peuvent adopter qu'une de ces dimensions à chaque fois, mais que les échanges entre les genres de pratique sociologique intégrent, positivement, la profession. Voici la structure de l'article : 1) il situe le sociologue dans le contexte de sa profession, en faisant attention au caractère disciplinaire en vigueur ; 2) qui est lui-même façonné suivant différents régimes politiques nationaux ; 3) pour finalement atteindre la dimension globale. La conclusion générale est que les sociologues ne gravitent pas dans un espace vide au-delà de l'économie, mais ils accomplissent leurs missions dans des champs idéologique et politique, qui sont régionaux et nationaux avant d'être globaux. Reconnaitre ces champs, c'est la première tâche pour n'importe quel engagement critique ou projet politique, car ils constituent les briques de toute Sociologie internationale.

MOTS-CLÉS : Sociologie publique ; niveaux national et global ; intellectuel ; Immanuel Wallerstein ; pratique professionnelle. 